Revista Española de Antropología Americana ISSN: 0556-6533

https://doi.org/10.5209/REAA.61974

\title{
Changos en el Puerto de Cobija. Transformaciones sociales durante el siglo XIX
}

\author{
Javiera Letelier Cosmelli ${ }^{1}$ y Victoria Castro Rojas ${ }^{2}$
}

Recibido: 4 de octubre de 2016 / Aceptado: 8 de marzo de 2017

Resumen. Se analiza el desarrollo histórico durante el siglo XIX de los grupos cazadores-recolectores marítimos denominados «changos» en el Puerto de Cobija, región de Atacama, Chile. Se establece como eje las transformaciones sociales, culturales y económicas vinculadas al nacimiento de los estados naciones en América y el consecuente desarrollo local del capitalismo industrial en la costa desértica. Estas transformaciones dan cuenta de una nueva identidad costera que mantuvo elementos propios de la tradición changa como el uso de las balsas de cuero de lobo marino; no obstante, mutó en el marco de la creación del primer puerto de Bolivia.

Palabras clave: Changos, siglo XIX, capitalismo industrial, Puerto de Cobija.

\section{[en] Changos in the Port of Cobija. Social Transformations during the $19^{\text {th }}$ Century}

\begin{abstract}
We analyze the historic development of maritime hunter-gatherers called Changos during the $19^{\text {th }}$ century in the port of Cobija, region of Atacama, Chile. We consider the social, cultural and economic transformations linked to the birth of nation states in Latin America and the consequent local development of industrial capitalism on the desert coast. These transformations reveal a new coastal identity that maintained elements of Chango tradition, such as the use of seal leather rafts; however, it changed in the context of the creation of the first Bolivian port.
\end{abstract}

Keywords: Changos, $19^{\text {th }}$ century, industrial capitalism, port of Cobija.

Sumario. 1. Introducción. 2 Los changos en Cobija durante la República. 3. La transformación en la subsistencia de los changos. 4. Palabras finales. 5. Referencias.

\section{Introducción}

Los changos, emplazados en la actual costa chilena entre los 17 y los 30 grados de latitud sur (Castro 2009), constituyen una categoría étnica que se rastrea desde el Periodo Colonial para grupos de cazadores-recolectores marítimos «con organización social igualitaria y no centralizada, distinguiéndose una multiplicidad de entidades sociales que posiblemente se reconocieron como distintos pero que a su vez cuentan

\footnotetext{
1 Universidad Austral de Chile, sede Puerto Montt. javiera.letelier@uach.cl

2 Departamento de Antropología, Universidad Alberto Hurtado, Santiago de Chile. vcastror53@gmail.com
} 
con elementos en común» (Letelier 2011: 112). En este contexto, los diversos grupos costeros poseyeron distintas denominaciones; no obstante, la de chango se generalizó durante el siglo XIX para referirse a los grupos cazadores-recolectores marítimos que utilizaron balsas de cuero de lobo y se extendieron desde el sur de Perú hasta Tongoy (Letelier 2011). Esta amplitud longitudinal abarcó una zona extensa de costa desértica con abundante nubosidad que se subdivide en dos áreas geográficas ambientales particulares. El área sur comprende un sistema de valles transversales que se extiende desde la cuenca del río Aconcagua en el sur hasta la cuenca del río Copiapó en el norte. La segunda región ambiental se extiende hacia el norte de Atacama en la costa desértica, con precipitaciones escasas y ausencia de cursos de agua permanentes (Novoa et al. 2008).

Pese a que la costa de Atacama presenta un ambiente árido, la franja litoral costera ofrece condiciones excepcionales para el desarrollo de ecosistemas de alta productividad gracias a la influencia de la corriente fría de Humboldt, la que «genera un ambiente rico en nutrientes, atractivo para una gran abundancia y diversidad de especies marinas» (Olguín et al. 2014: 179). Estas condiciones, interrumpidas periódicamente por otros fenómenos como la corriente del Niño y la Niña, permitieron que esta zona se constituyera en un foco de recursos (Olguín et al. 2014; Sandweiss 2003), observándose desde momentos tempranos adaptaciones humanas y el uso de tecnologías singulares para su explotación.

En este trabajo nos centramos específicamente en el análisis de los grupos changos asentados en la zona de Cobija durante el siglo XIX, ya que, como primer puerto de Bolivia ${ }^{3}$, se convirtió en un enclave multiétnico que buscó potenciar el desarrollo comercial e industrial de esta nación (Aillón 2007). La configuración del puerto como nuevo núcleo comercial de Bolivia produjo un aumento y diversificación poblacional. Esta situación devino en una temprana desestructuración de los modos de vida tradicionales (Ballester et al. 2010).

La rada de Cobija se localiza aproximadamente entre las actuales ciudades costeras de Tocopilla y Mejillones (Lofstrom 1974) (Figura 1). Su fundación ocurrió en 1587 bajo el nombre de «Santa Magdalena de Cobija» y administrativamente dependió, durante el Periodo Colonial, del corregimiento de Atacama, concretamente de la región de la Atacama la Baja o la Chica, cuyos límites por la costa se extendieron desde Tocopilla y Cobija hacia el norte y de Morro Moreno hacia el sur y al interior, abarcando la hoya del río Loa y sus afluentes. A su vez, el corregimiento dependió de la Audiencia de Charcas, cuya capital fue la ciudad de La Plata. El puerto, desde sus inicios, sirvió de refugio a los marinos en un tramo de la costa particularmente inhóspito (Fifer 1976) que, tras dos maremotos durante el siglo XIX y el desarrollo de otros enclaves económicos, cayó en desuso (Aldunate et al. 2008) ${ }^{4}$.

Históricamente la zona de Cobija constituyó un área en donde se asentaron diversos grupos pescadores que compartieron una identidad en torno a los medios de subsistencia y sus tecnologías. Entre los elementos que sostienen esa identidad común destaca la dependencia con respecto al mar y el desarrollo de tecnologías asociadas (Llagostera 1982) -la navegación y la pesca-, pero especialmente resalta

3 La rada Cobija se bautizó oficialmente, en el momento de su creación como puerto boliviano, con el nombre de Puerto Lamar, en honor al general José de la Mar, prócer americano nacido en la presidencia de Quito. No obstante, en la práctica, se siguió denominando Cobija (Téllez y Silva 2012).

4 Desde 1879, tras la Guerra del Pacífico, la región de Atacama en donde se emplaza Cobija pasó a ser territorio chileno. 
Figura 1. Mapa geográfico con las principales ciudades de la costa e interior del tramo central y norte de Chile. (Gentileza de Fernando Maldonado).

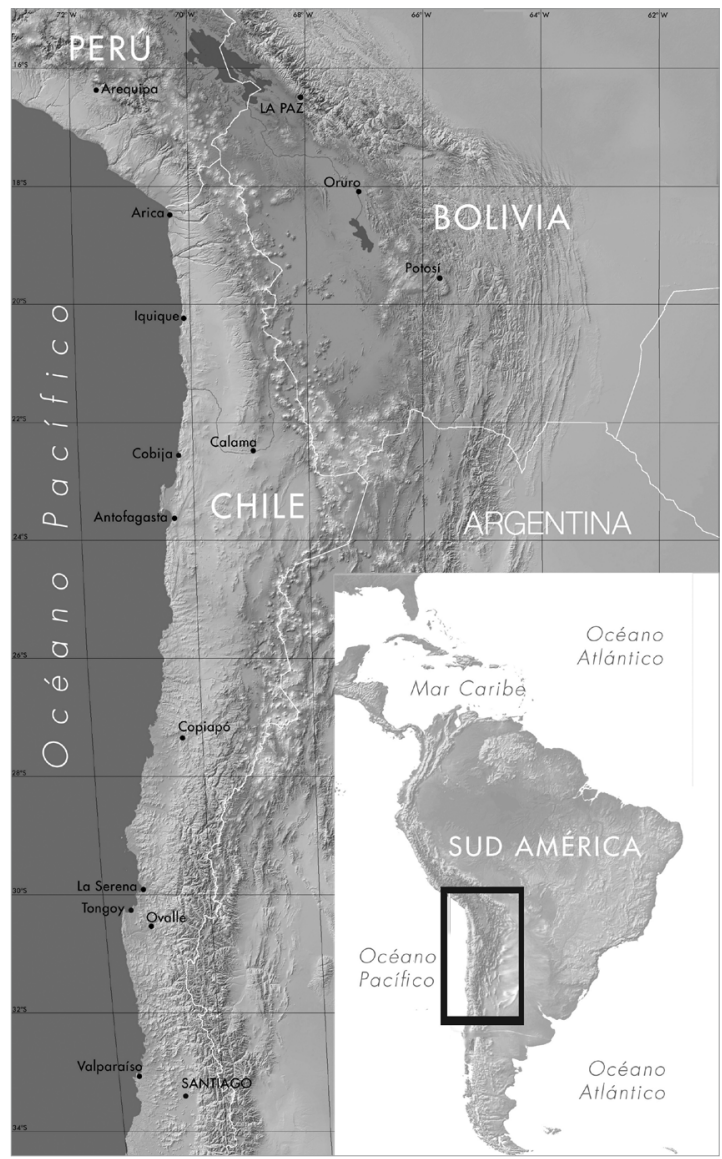

el desarrollo de una complejidad ideológica en torno a la percepción de la muerte y el tratamiento de los cuerpos, ejemplificada por los grupos Chinchorro.

Las primeras ocupaciones de estos grupos cazadores-recolectores marítimos en la zona presentan cronologías que van desde el 6000 al 3000 a.C. - correspondientes al periodo Arcaico-, destacando el desarrollo de grupos culturales con una fuerte tradición de caza y recolección marítima con posible presencia de navegación temprana (Bittmann 1980; Castro et al. 2012). A fines del periodo Arcaico, la caza y la recolección se mantuvieron y se integraron nuevas formas de habitar el espacio vinculadas a la práctica del entierro bajo los pisos de estructuras habitacionales (Castro et al. 2012).

En este sentido, la costa que se extiende desde el litoral de Tarapacá hasta la costa semiárida del Choapa fue un núcleo de pescadores andinos sustentados sobre la base de una tradición marítima que fue evolucionando a través del tiempo. Esta tradición se remonta al Arcaico Temprano, con la conquista de la dimensión longitudinal - la explotación de recursos de orilla- que desarrollaron los grupos cazadores-recolectores costeros. Hacia el 7500 a.C. las poblaciones costeras adquirieron la dimensión batitudinal -acceso a recursos de profundidad mediante la aparición del anzuelopara, finalmente, conquistar la dimensión latitudinal, es decir, el acceso mar adentro que implicó el uso de embarcaciones apropiadas (Llagostera 1982, 2005). 
La transición hacia el Periodo Formativo en la zona se describe a partir de varios indicadores, entre los que se cuentan el incremento en la construcción de caminos que conectaron las tierras altas con la costa y también la presencia de túmulos funerarios en el área. Estos últimos constituyen parte de una tradición de entierros que se extiende desde Arica - con la tradición Alto Ramírez- hasta Cobija, en donde se integra el factor de la visibilidad a las formas del uso del espacio fúnebre costero (Castro et al. 2012).

La integración con las tierras altas -especialmente con la zona atacameña- se intensificó durante el periodo Intermedio Tardío, destacando en la costa la presencia de materiales provenientes de aquellas -cerámicas del interior-, además de restos

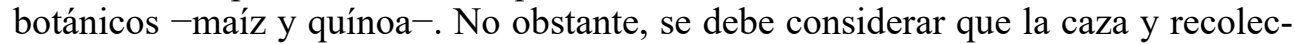
ción marítima siguieron siendo fundamentales (Castro et al. 2012).

El periodo Tardío se caracterizó por el dominio incaico, aunque el sector no presenta un extenso registro que dé cuenta de ello. No obstante, se plantea que los incas se habrían interesado en esta localidad principalmente por sus recursos mineros (Castro et al. 2012). Políticamente, esta área constituyó parte de los suyus incaicos (Castro 2001) lo que hace factible plantear que estos correspondían a divisiones previas (Rostworowski 1986) a la hegemonía incaica. Específicamente, este sector comprendió parte de lo que se denominó el Colesuyu, el cual abarca desde el sur de Perú, en concreto los valles de Camana, hasta Tarata y el norte de Chile-desde Arica hasta Tarapacá- (Rostworoswki 1986), insertándose así dentro del Área Centro Sur Andina que comprende ambientes diversos establecidos en distintos pisos ecológicos vinculados al desarrollo de la ecocomplementariedad (Castro 2001).

Durante el Periodo Colonial los grupos cazadores-recolectores marítimos del área de estudio aparecen nombrados tempranamente por cronistas durante los siglos XVII y XVIII y posteriormente por viajeros a fines del siglo XVIII, en donde se destaca la presencia de diversas denominaciones, como changos 5 , camanchangos, camanchacas $^{6}$, pro-anches ${ }^{7}$, uros y puquinas ${ }^{8}$, nombres que probablemente se vincularon con diferenciaciones basadas en criterios lingüísticos, territoriales e identitarios (Bitman 1983; Castro 2009; Lehnert 1997; Letelier 2011). Fue la categoría de chango la que desde el siglo XIX se constituyó en concepto genérico vinculado a una identidad productiva costera (Letelier 2011), «independiente de su origen étnico» (Martínez 1990: 20).

\footnotetext{
5 Según Rostworowki (1986) «chango» vendría de las palabras Camanchangos o Camanchacas. Este último concepto, se refiere a la forma con que se denomina localmente a la vaguada costera (Rostworowski 1986). Esta denominación se documenta, para 1578, por Francis Drake (Castro 2009) y, entre 1612 y 1659, en el «Libro de varias ojas» (Lehnert 1997).

6 Denominación señalada por Lizárraga, quien estableció que los changos poseen una «costra colorada, durísimo; dicen les proviene de la sangre que beben de los lobos marinos, y por ese color son conocidísimos» (Lizárraga 1968 [1594-1608]: 148).

7 La denominación pro-anches, según el «Libro de varias ojas» (Casassas 1974a), se refiere a población de Caldera y Cerro Moreno, lugares emplazados al sur de Cobija, durante el siglo XVI; el vocablo podría provenir del quechua purum auca o poro auco que pudo haber sido aplicado a grupos costeros no sometidos (Cassasas 1974b). No obstante, la argumentación es débil (Letelier 2001).

8 La denominación uros o puquinas (Rostworowski 1986) se refirió, posiblemente, a grupos que originalmente vivían en las islas y las orillas del lago Titicaca. Por ello, su uso para referirse a los cazadores-recolectores marinos puede relacionarse con la actividad de subsistencia más que con grupos particulares, conceptualización que habría tenido una connotación negativa. El nombre de puquinas o «colorados» vendría, según Cuneo Vidal, de las manchas rojizas en la piel producto de la ictiofagia (Castro 2009).
} 


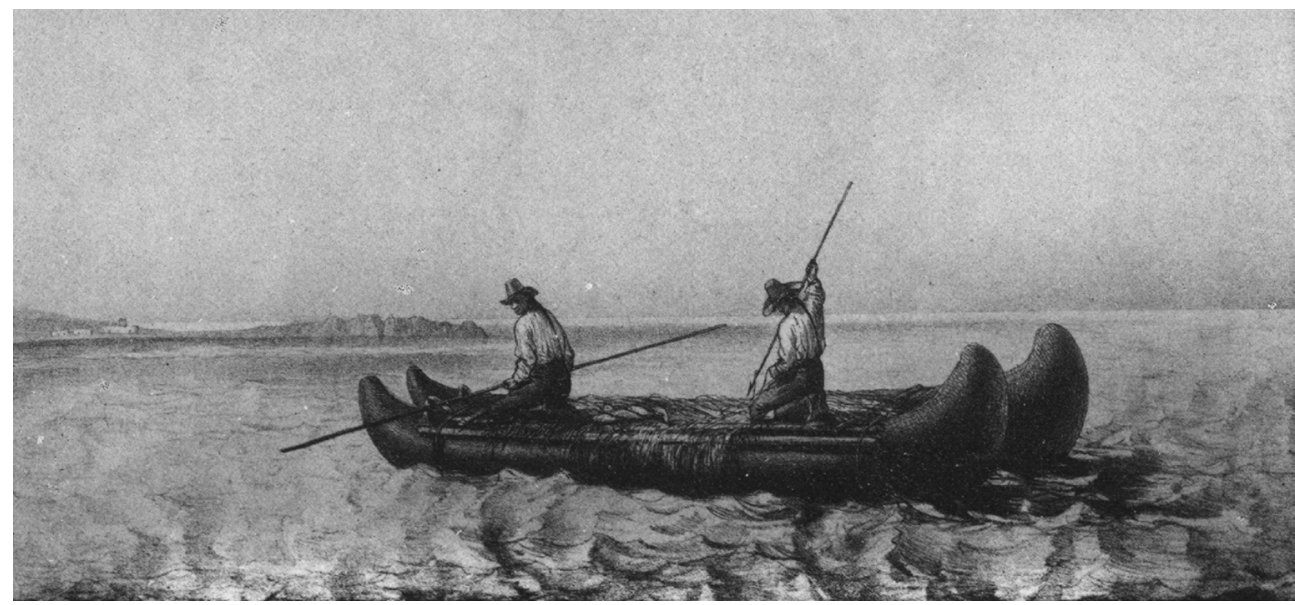

Figura 2. Balsa de cuero de lobo marino con dos changos en Cobija (D’Orbigny 1945 [1835]: 664).

Durante el Período Colonial y posteriormente a inicios republicanos los changos aparecen escasamente registrados en la documentación, ya que se consideraba una población bárbara que se caracterizó de forma reducida por tres aspectos (Bitman 1980): en primer lugar, su condición de vida miserable, la que se ligó a su posición de indio y en específico de indio cazador-recolector marítimo; en segundo lugar, su carácter móvil vinculado a su patrón de asentamiento disperso sin aldeas permanentes, asociado a las actividades productivas marítimas (Letelier 2011); y, en tercer lugar, el aprovechamiento intensivo del lobo marino, especialmente para la construcción de balsas, pero también para viviendas, vestimentas, recipientes, cordelería y alimento (Figura 2).

\section{Los changos en Cobija durante la República}

La creación de Cobija se vinculó al nacimiento del estado boliviano bajo los ideales de desarrollo de la actividad comercial (Aillón 2007), que comprendían una política económica minera extractiva con orientación externa (Mitre 1981). En ese contexto económico fue necesario el impulso de un puerto propio que permitiera disminuir los costos de envío y recepción a Buenos Aires y Arica, ser parte del comercio transmarítimo y, así, fortalecer el intercambio comercial a escala mundial.

A fines de 1825 Antonio José Sucre desarrolló una serie de reformas políticas y económicas que buscaron la revitalización de la minería de la plata a través del establecimiento de un nuevo sistema administrativo. Este consistía en la introducción de capitales y tecnología extranjera con el objetivo de mejorar el transporte y la comunicación; es en este contexto que la existencia de un puerto se tornó fundamental. La elección del puerto fue encargada al Mariscal Francisco Burdett O'Conner, militar y hombre de confianza de Sucre (Kent 2009), quien debió levantar un mapa de la zona y ubicar en Atacama el lugar más apto para construirlo, proponiendo Cobija; allí halló únicamente a un cochabambino, de apellido Maldonado, quien manifestó que sus indios changos habían muerto de viruela (Cajías 1975). 
La habilitación del puerto fue lenta, debido a la inexistencia de una infraestructura adecuada para el desarrollo del comercio. Solo recién en 1827 se dio inicio a la habilitación formal de Cobija, aunque siempre resultó problemática por las condiciones desfavorables del desierto para un asentamiento de tipo urbano (Cajías 1975). Atendiendo a estas condiciones, Antonio José Sucre dictó un decreto el 10 de septiembre de 1827 con una serie de medidas tanto para atraer gente que se asentara en el puerto como para aumentar el uso de este en la zona (Baldivia 1951). Entre las medidas destacó la entrega de un terreno de veinte varas de frente y cincuenta de fondo a todo aquel avecindado en el Puerto Lamar y sus alrededores, fueran nacionales o extranjeros. A su vez, para cada familia indígena que se trasladara a Cobija, el decreto establecía que quienes se asentaran a diez leguas del contorno del puerto gozarían de exención tributaria - por tres años- $-\mathrm{y}$, por cuenta del Gobierno, se les entregaría dos burros, dos vacas o bueyes, diez carneros, herramienta de agricultura para dos personas y cuatro topos ${ }^{9}$ de tierra. No obstante, si se establecían en el Puerto Lamar tendrían la mitad de los beneficios ya descritos. Estos beneficios también fueron otorgados a extranjeros que se trasladaran a cualquier rincón de Atacama (Baldivia 1951). En noviembre de 1825 el periódico El Cóndor publicó una lista de reparto de terrenos en el puerto; entre los propietarios se encontraban Horacio Álvarez, Francisco Burdett O'Connor y Lucas de la Cotera. Este último y Bartolomé Fernández fueron los primeros comerciantes acaudalados en arribar al puerto (Cajías 1975).

Pese a lo anterior, el panorama demográfico de la costa era bastante desolador con respecto al resto de la república en las primeras décadas del siglo XIX. Dentro de la población mayoritaria se encontraban inmigrantes europeos y bolivianos, mientras que los indígenas sumaron un número marginal correspondiente a changos $\mathrm{y}$, en el caso de la mayoría de los arrieros, a atacameños no residentes en Cobija. De tal modo, la sociedad de Cobija se conformó sobre la base de una complejidad que se acentuó por la convivencia de los diversos actores sociales que participaron en este espacio.

Esta nueva convivencia e integración en un sistema mercantil a mayor escala generó transformaciones en las poblaciones costeras locales, pero manteniendo su carácter marginal en relación con el resto de los habitantes del puerto, debido a su continuidad con un modo de vida cazador-recolector marino tradicional (Aldunate et al. 2010). Esto puede ejemplificarse, por una parte, a través de una carta enviada por el administrador de la Aduana de Cobija al Ministro del Interior boliviano en 1828, donde establece que en el puerto no hay más de 100 personas. Sin embargo, no cuenta a los visitantes esporádicos ni a los pescadores. Estos últimos, «solo están cuando hay pesca y luego se trasladan a otra caleta donde la encuentran» (Cajías 1975: 94).

Por otra parte, en la observación realizada por el gobernador del Puerto de Cobija Atanasio Hernández sobre esta localidad en 1830, al referirse a su población local, detalla cuidadosamente la condición salvaje y pobre de los pescadores que considera son los descendientes indígenas del puerto:

«Cabe mencionar en este lugar de los antiguos habitantes de esa costa y particularmente del Puerto. Ellos descienden de nuestros antepasados Indígenas por su color. Son esencialmente pescadores, y no tienen domicilio fijo. En las diferentes estaciones del año siguen el curso en la pesca por toda la costa, y son unas tribus nómadas y errantes. Sus costumbres son raras y algo montaraces- Hablan generalmente el idioma español, y además conversan un lenguaje particular que en nada se parece á los de

\footnotetext{
9 «Topo» podría venir de tupu, que significa legua de camino a la medida del inga (Bertonio 1984 [1612]: 365).
} 
país- En todo el curso de la evolución hán vivido á su arvitrio sin mas que una dependencia nominal hacia el Gobierno en Atacama, q. ${ }^{\mathrm{n}}$ les nombrara un Alcalde. Viven constantemente casi al raso: nada es mas insignificantes que sus ramadas, si aun este nombre puede darse á sus miserables aduazes. Toda su hacienda consiste en una balsa en odres, algunos malos instrumentos de pesca, y cuatro trozos de madera para formar la choza que cubren por el techo con una piel de Lobo. Se afectan sin embargo en una veneracion religiosa acia, su antigua capilla que aun ecsite en ese Puerto; y es cierto que para atraer á estas familias á la vida sociales es muy interesante el establecimiento de una Doctrina tanto mas cuanto el Parroco de Cobija tiene su residencia á 50 leguas sobre el interior» (ANB, Ministerio del Interior, Tomo 31, Legajo 22, f. 3-4, 1830) ${ }^{10}$.

Atanasio Hernández da cuenta de la forma de vida de los changos destacando aspectos que guardan relación con sus viviendas y con la condición de movilidad, siendo la balsa la herramienta más relevante. Asimismo, señala la importancia de la antigua capilla y de la religión en el ámbito local, lo que se condice con la tradición temprana de extirpación de idolatrías expresada en el documento de Francisco de Otal, cura de la provincia de Atacama La Baja, quien, en su probanza de méritos de mediados de siglo XVII, señala su enseñanza a los indios naturales de Cobija «della mucha cuidado y diligencia los preceptos de nuestra Santa Fee y religión cayholica e misterios de ella castigando y etirpando las ydolatrias de dichos naturales» (Castro 2009: 493).

Con respecto a la organización de parentesco, llama la atención el carácter endogámico de los changos. Esto se rastrea desde momentos coloniales en el «Libro de varias ojas» que contiene el registro, entre 1611 y 1698 (Casassas 1974a), de partidas de bautizos y matrimonios; en él se observa que «prácticamente todos aquellos matrimonios de camanchacas son endogámicos, sin figurar ningún matrimonio entre camanchacas y atacamas» (Aldunate et al. 2010: 344). Ello se condice con lo observado en los Censos locales de 1840 y 1841, en donde la gran mayoría de los pescadores, posiblemente changos, poseían los mismos apellidos, repitiéndose intensamente los casos de Armendares, Maturana, Maldonado y Sajaya. A la sazón, tomando la propuesta de Aldunate y colaboradores (2010), la endogamia changa no sería difícil de explicar por las diferencias evidentes entre changos y atacameños, considerando que estos últimos poseían un débil vínculo con el mar y con lo que este implicaba a nivel de subsistencia y cosmología para los grupos cazadores-recolectores marítimos.

\section{La transformación en la subsistencia de los changos}

Uno de los aspectos fundamentales para comprender el proceso de transformación de la población changa está en la relación de estos con el medio costero y el modo en que se integraron, desde un área periférica, en un contexto mundial de desarrollo del capitalismo industrial. Pese a la modificación de conductas que ello supuso, dichas poblaciones mantuvieron un apego hacia el modo de subsistencia marino que se ejemplifica a partir de aspectos tecnológicos como la continuidad del uso de las balsas de cuero de lobo. En este contexto destaca lo señalado por D'Orbigny respecto a las balsas:

«Es con esas embarcaciones [...] que tanto de rodillas, tanto sentados en la delantera y remando por medio de una larga pértiga empleada de ambos lados alternativamente

\footnotetext{
${ }^{10}$ Se ha respetado, en esta cita y las siguientes, la grafía de los textos originales.
} 
a derecha e izquierda, van a cazar a los lobos marinos, muy comunes en toda la costa. Las emplean, por lo general, para llegar a alta mar; allí espían a los peces, los siguen con mirada penetrante en el seno de las olas y eligen el momento favorable para arrojar con extrema destreza un pequeño arpón, que difícilmente no alcanza su objetivo» (D’Orbigny 1945 [1835]: 936).

No obstante, su integración en el sistema de Cobija generó que las actividades tradicionales también se transformaran, a la luz de la nueva dinámica portuaria. Los changos, por tanto, se sumaron con intensidad a labores portuarias y navales, especialmente la carga de buques:

«También se efectúa con esos barcos livianos el contrabando entre los comerciantes del país y las naves ancladas en la rada, de las mercaderías prohibidas, tales como la plata piña y otros objetos de gran valor; por esos cada casa tiene a su balsero titular, siempre depositario de grandes riquezas y siempre personalmente en la miseria más absoluta, tanto él como su familia. Hombres abnegados, esos balseros están dispuestos a todo. Su probidad es conocida, al punto que nunca se les teme hasta cuando son instrumento de una operación importante y encargado de grandes valores» (D’Orbigny 1945 [1835]: 936).

En esta misma línea, el periodista inglés Howard Russell (1890), de The Ilustrated, que realizó por cargo de John Thomas North una publicación con ilustraciones de Milton Prior en torno a la explotación salitrera en 1889, indicó la presencia de changos cargueros en la zona de Pisagua, aproximadamente a $300 \mathrm{~km}$ al norte de Cobija, a los que denominó Balsa men (Figura 3). Estos hombres, según su descripción, eran capaces de cargar hasta 25 toneladas de salitre en media hora a través de balsas o flotadores hechas de pieles de lobos marinos cosidos en los extremos en forma de cigarros, inflados a pulmón.

Asimismo, esta nueva dinámica socioeconómica incluso habría permitido que los changos ampliaran su rango de movilidad costera. Ello se ejemplifica a través de la siguiente declaración de Teodoro Espinosa, que data de 1850:

«...asegurado de ser de 25 años de edad, soltero, natural de chango República chilena, empleado en el Buque titulado Illimani en la clase de moso y sirviendo en la marina [...] que servir en dicho buque que hace 3 meses que envian desde Valparaiso después de haber regresado de Talcahuano de donde trajeron arinas y maderas y descargaron en Valparaiso quedando parte de la arina recibieron otros cargamentos de cajones y arinas con los que se dirijieron a este puerto» (AGH Fondo Bolivia, Vol. 1, 1850).

En este relato destaca el incremento en la movilidad en embarcaciones, ya no necesariamente las balsas de cuero de lobo, sino como empleados en naves mercantes, llegando incluso al sur de Chile. En tal sentido, la movilidad por la costa, que fue un aspecto tradicional de estas poblaciones, se mantuvo con posterioridad a las independencias de Bolivia y Chile e incluso se intensificó a la luz de las transformaciones sociopolíticas y económicas propias de la dinámica capitalista industrial y la integración de las poblaciones cazadoras-recolectoras en labores vinculadas al mar, pero no dentro de su ámbito tradicional de vínculo con éste.

Por otra parte, los changos se integraron fuertemente en las labores mineras, especialmente en el marco del pirquineo. Los ejemplos de ello se extienden desde Copiapó al norte, abarcando para ese periodo tanto territorio chileno como boliviano. Rodolfo Philippi señala, a mediados del siglo XIX, lo siguiente sobre un grupo de atacameños: 


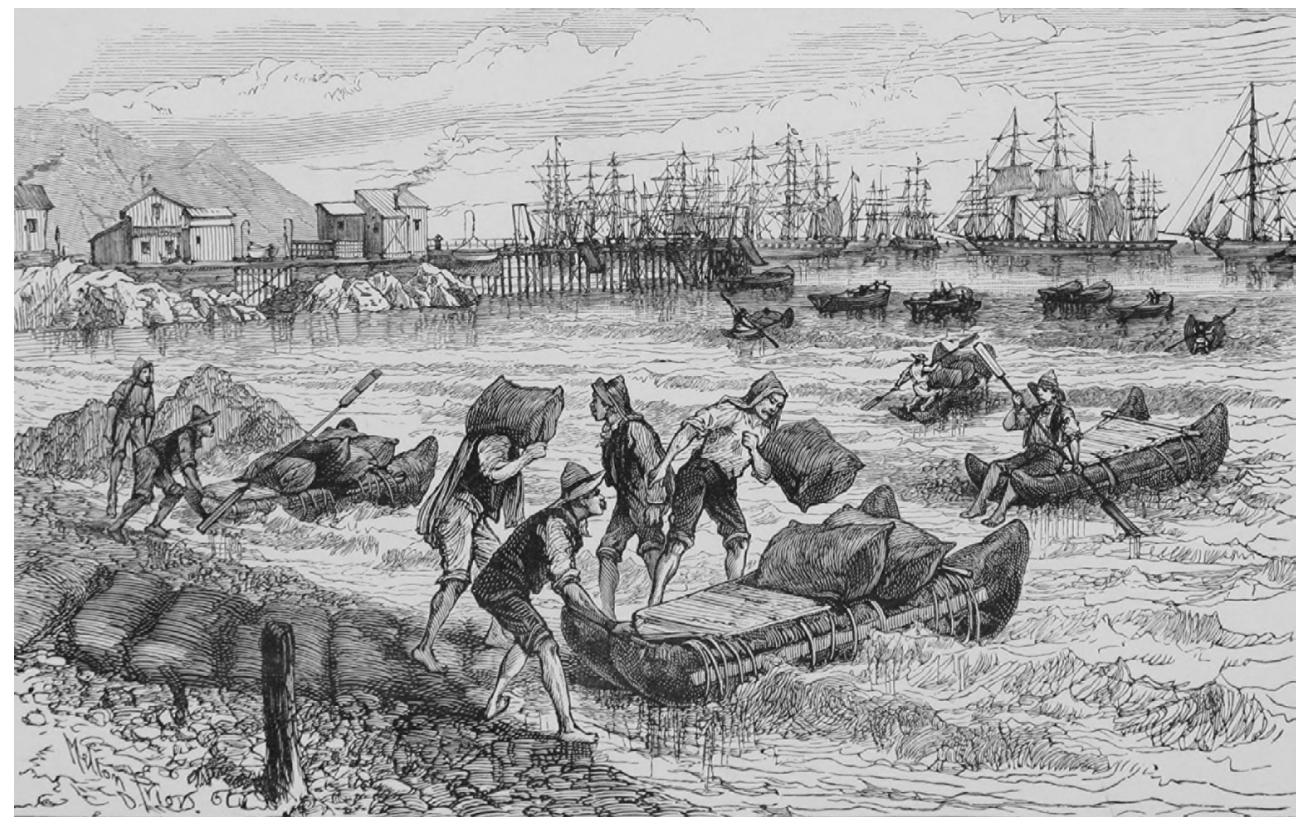

Figura 3. Balsa men and balsas, Pisagua (Russell 1890: 234).

«Habiendo la guerra entre Perú y Bolivia hecho imposible el comercio entre Cobija y Atacama, estos indios habían pensado emplear sus mulas en una expedición a Paposo para cambiar por coca -el uso de mascar las hojas de coca, tan general en Bolivia y Perú, está igualmente esparcido entre los changos- congrios y mariscos secos y vender éstos en las provincias argentinas. Llegados a la costa hallaron, sin embargo, sus esperanzas en gran parte frustradas, porque la mayor parte de los changos, en vez de dedicarse a la pesca, habían preferido trabajar en las minas; los atacameños, pues habían podido comprar solamente una cantidad pequeña de pescado» (Philippi 1860: 32).

De tal modo, la minería, que para los changos se habría erigido inicialmente como una práctica más bien complementaria, habría ido adquiriendo relevancia de manera exponencial, en función del aumento del valor del cobre en el mercado.

No obstante, se debe considerar que el desarrollo minero de la zona se extiende muy atrás en el tiempo, desde el periodo Arcaico Temprano (10.500-9000 a.C.), con la evidencia de pigmentos e industria lapidaria, y se incrementó hacia el periodo Formativo, en donde destaca la presencia de cuentas de collar de cobre (Salazar et al. 2010) y los inicios de la producción en oro. Asimismo, al menos para el período Intermedio Tardío (900-1400 d.C.) y vinculada a las prácticas de caza y recolección marítimas, destaca la evidencia de anzuelos de cobre (Salazar et al. 2010). En ese sentido, aunque el cobre que se extraía se pudo utilizar para instrumentos de pesca en tiempos republicanos, no hay evidencia material que lo sustente, por lo que es factible plantear que el producto de la explotación de cobre de las poblaciones costeras se habría vendido como materia prima a los empresarios locales, lo que permitía la obtención de circulante para el pago del tributo y para la subsistencia en un sistema con un creciente uso de la moneda. 
La explotación del cobre fue observada por William Ruschenberger (1835), médico norteamericano que narró su viaje a una milla de Gatico, localidad colindante a Cobija. En su relato detalló que, ascendiendo la ladera de los cerros por las quebradas a través de un sendero zigzagueante -más o menos a 1.300 pies--, se distinguían varias bocaminas con profundidad no mayor a 15 o 20 pies. Junto a ello, describe la presencia de un toldo blanco en cuyo alrededor había media docena de chozas pequeñas, entre las cuales se distinguían cerca de 20 mujeres y niños, quienes rompían piedras y seleccionaban el mineral (Lofstrom 1991).

Recogiendo lo observado por Ruschenberger, los changos se habrían vinculado con la minería en un contexto de explotación artesanal, por lo que su relación con los empresarios mineros y las casas comerciales habría sido parcial, a diferencia de la establecida con los peones en el ámbito de explotación guanera y, posteriormente, salitrera desde mediados del siglo XIX en la zona.

Con relación a la presencia de niños y mujeres en Cobija, su registro es bastante escaso. Su condición de inferioridad de género, cuestión que no solo se ve entre los changos sino también entre la población no indígena, sostiene el imaginario del espacio salvaje y masculino representado tanto a través de los viajeros como de los mismos habitantes del puerto. En ese sentido, tomando los planteamientos de Osorio (2004) para el caso posterior del desarrollo de la explotación salitrera, vemos las raíces de la conformación de un espacio preponderantemente violento, violencia que se constituye como un rasgo dominante de la masculinidad.

Asimismo, además del escaso registro de la población femenina de Cobija, en los Censos de 1840 y 1841, las mujeres no aparecen normalmente asociadas a actividades laborales, a excepción de algunas pulperas y del caso de las changas (Figura 4), quienes aparecen en un número importante declaradas como pescadoras (ANB Ministerio de Interior, Tomo 87, legajo 26, 1840; ANB Ministerio de Interior, Tomo 80, legajo 25, 1841). Lo anterior da cuenta de que la división del trabajo tradicional de las poblaciones costeras no guardaba armonía con la tradición occidental, teniendo las changas un rol preponderante en el área productiva, específicamente en la caza y recolección marina. En ese sentido, ello podría ser el reflejo incluso del mantenimiento de la tradición recolectora y pesquera por parte de las mujeres, considerando que los hombres, posiblemente, hayan sido quienes asumieran las nuevas labores vinculadas al desarrollo del puerto, dejando la caza y recolección marítima en un segundo plano.

Por otra parte, la relación de los changos con la minería no solo se vinculó a la extracción, sino también al contrabando fuera de los circuitos tradicionales del movimiento de la plata, supeditados al control estatal. Los empresarios locales generaron circuitos de contrabando alternativos que incluyeron alianzas con changos y arrieros. Esta dinámica se vio fuertemente reflejada en la década de 1830 en Cobija, periodo en el cual el puerto contaba con escasa población y cuyo gobierno se encontraba subordinado a los intereses de los empresarios locales, existiendo un control laxo de los delitos de contrabando. Lo anterior queda ejemplificado en septiembre de 1830 cuando los empresarios Francisco Arana y D. Rafael Beche y Garayo se vieron implicados en el contrabando de seis piñas supuestamente venidas desde Salta. Estas fueron bajadas por el arriero Mariano Holcay por Punta Tames, lo que levantó la sospecha de la esposa de Gavino Barrera, postero de Chacance, quien alertó a las autoridades de la situación. Las piñas supuestamente debían ser embarcadas por el chango Diego Almendares (ANB, Ministerio de Hacienda, Tomo 217, Nº17, f163, 


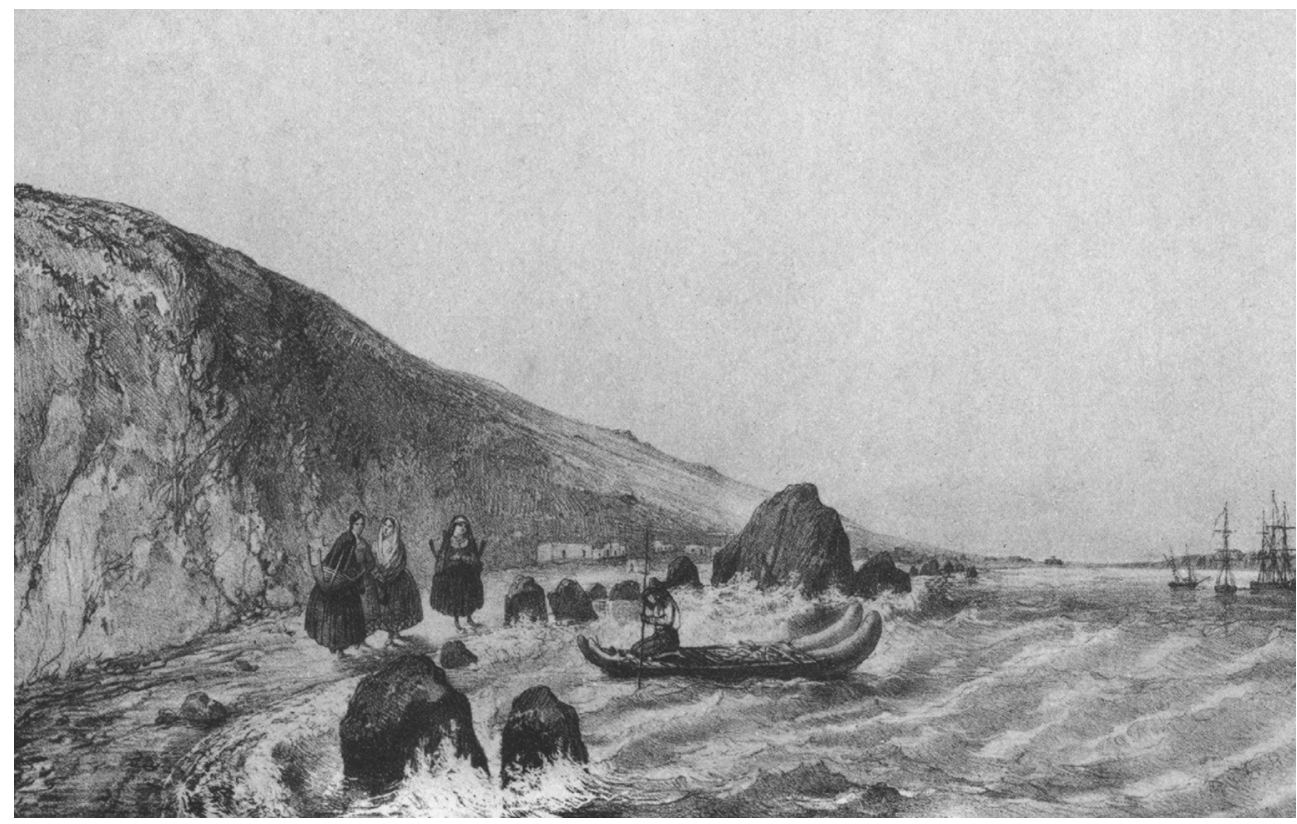

Figura 4. Changas en Cobija (D’Orbigny 1945 [1835]: 648).

1830). El balsero José Gonsales de veinte seis años, natural de Iquique y también involucrado en el caso de contrabando, declaraba lo siguiente:

«Que Don Rafael Beche, le habló para que fuese con su balsa a Tames, y que le contestó que el no podia pasar para arriba, y entonces le dijo Beche: lléveme U. hasta aquel punto, y fué con el hasta la agua de mulatos, donde encontraron a Diego Almendares quien le dijo a Beche; las cargas las ha tomado un oficial y las ha vuelto $\mathrm{p}^{\mathrm{a}}$ atrás» (ANB Ministerio de Hacienda, Tomo 217, Legajo 17, f.164, 1830).

Asimismo, considerando las declaraciones del balsero Gonsales, es relevante recordar que el mismo D`Orbigny señaló que los changos trasladaban productos costosos hacia los barcos. Es más, cada casa comercial tenía a su balsero titular, estableciéndose una relación pactada (D’Orbigny 1945 [1835]), de la cual, lamentablemente, hay escaso registro.

Por otra parte, los grupos costeros establecieron relaciones constantes con poblaciones del interior, cuestión que se evidencia desde momentos prehispánicos y que se mantuvo, destacando los relatos de intercambio de productos de interior como la coca por charquecillo ${ }^{11}$ (Philippi 1860). Se observa una tradición de movilidad en donde la tendencia fue que la población de tierras altas se movilizaba hacia la costa, cuestión que se rastrea desde momentos prehispánicos y durante el Periodo Colonial (Sanhueza 1992; Letelier 2016). Por su parte, la población costera, según el registro histórico, se mantuvo principalmente en el litoral, subiendo a tierras altas con menor regularidad. Lo anterior se relaciona con la información contenida en los Censos locales (ANB Ministerio Interior Tomo 87, Legajo 25, 1840; ANB Ministerio de Interior, Tomo 80, Legajo 26, 1841), destacando que en 1840 solo un arriero residía

\footnotetext{
${ }^{11}$ Pescado seco y salado.
} 
en Cobija y, en 1841, únicamente cinco, siendo este un número muy pequeño con relación al volumen de movimiento que el puerto requería si se considera que Cobija era el principal puerto de Bolivia (Letelier 2016).

\section{Palabras finales}

Las poblaciones changas fueron constituidas por diversos grupos cazadores-recolectores que compartieron tradicionalmente una identidad caracterizada por su vínculo con el mar, sus relaciones de parentesco y la división social del trabajo, entre otros elementos. Esta identidad tradicional se modificó a la luz de la integración en el sistema capitalista industrial desde el Periodo Colonial, pero especialmente durante el siglo XIX con el nacimiento de los Estados nacionales.

Es en este contexto que las poblaciones changas de Cobija fueron parte elemental del nuevo sistema portuario. Así, contribuyeron al desarrollo del puerto, pero laborando principalmente, desde su especialización costera, en trabajos como cargueros y empleados de barcos y, a su vez, manteniendo la caza y recolección marítima. Junto con lo anterior, se observa una intensificación de la explotación minera, especialmente del cobre, en el contexto de un sistema extractivista del que fueron partícipes los changos, dejándose por parte de los pescadores el sistema de subsistencia tradicional costera como forma productiva única (Larraín 1994; Letelier 2011). Esta explotación permite apuntar que, pese a los cambios en la intensidad y la tecnología de extracción del cobre, su desarrollo como actividad de los grupos costeros se fundó en una tradición previa a la ocupación hispana. A lo anterior se suma el que no aparezcan changos en el registro histórico vinculados con la extracción de otros productos como el guano y el salitre; no obstante, esta ausencia puede deberse al sesgo derivado de la escasa información sobre estas poblaciones contenida en el registro escrito y de la dificultad de identificar a las poblaciones costeras en actividades de carácter industrial a partir del registro arqueológico histórico.

Por lo tanto, los changos compartieron una identidad milenaria que se sustentó en uno de los elementos más notables del escenario local: el mar, siendo una de sus características más notables el desarrollo de tecnologías asociadas (Llagostera 1982), tales como la navegación, el uso de balsas de cuero de lobo y la pesca. En la actualidad persiste una amplia tradición de pesca y recolección en las costas de Chile manteniendo prácticas de movilidad y explotación similares, lo que se explica, desde las hipótesis de autores como Martínez (1985), señalando que el ser chango hace referencia, sobre todo, a una identidad productiva. En tal sentido, los changos no desaparecieron súbitamente, sino que se integraron en un sistema mercantil asociado con la pesca artesanal y con otras actividades como la minería (Letelier 2011).

Agradecimientos: Agradecemos al Archivo Nacional de Bolivia y al Archivo del Ministerio de Relaciones Exteriores de Chile. Se extienden agradecimientos a los proyectos de investigación FONDECYT N 1100951 y Anillo Soc 1109 y a los investigadores Sergio González Miranda y Pablo Artaza Barrios. Se agradece a Fernando Maldonado la elaboración del mapa, a Dafna Goldschmidt la lectura acuciosa del artículo y a los editores y revisores de la presente publicación. 


\section{Referencias}

\subsection{Referencias documentales}

AGH (Archivo General Histórico, Ministerio de Relaciones Exteriores de Chile, Santiago) Fondo Bolivia, Vol. 1: «Copia de la causa seguida en Cobija al Capitan de la barca nacional 'Illimani'», 1850.

ANB (Archivo Nacional de Bolivia, Sucre)

Ministerio del Interior, Tomo 31, Legajo 22, f. 3-4: «Observaciones que el comisionado A. Hernandez dirije al Supremo Gobierno sobres los diferentes ramos de ecsistencia y progreso del Puerto Lamar», 1830.

Ministerio de Interior, Tomo 80, legajo 25, foja 3-15: «Senso Individual y nominal de ambos sensos de los habitantes de este Puerto Lamar, con esprecion de clases, edades y condiciones, segun lo demuestra la siguiente relación, practicada por el Vicepresidente del Concejo Municipal en 20 de Enero de 1841», 1841.

Ministerio de Interior, Tomo 87, legajo 26, foja 4-11: «Senso Individual y nominal de ambos sensos de los avitantes de este Puerto, con especificación de sus clases, edades y condiciones, según lo demuestra la siguiente relación, practicada por el Vicepresidente del Concejo Municipal de esta Capital, en 20 de Enero de 1840», 1840.

Ministerio de Hacienda, Tomo 217, Legajo 17, f.163-164: «Declaraciones pr contrabando de plata, implicados Beche, Arana y Garayo, Sebastián Carmona (mozo), el arriero Mariano Holcay, el chango D. Armendares (chango) y el balsero Jose Gonsales», 1830.

\subsection{Referencias bibliográficas}

Aldunate, Carlos, Victoria Castro y Varinia Varela

2008 «San Bartolo y Cobija: testimonios de un modo de vida minero en las tierras altas y la costa de Atacama». Estudios Atacameños 35: 97-118.

2010 «Los atacamas y el pescado de Cobija en homenaje a John Víctor Murra». Chungará 42 (1): 341-347.

AILlón SORIA, Esther

2007 «En torno a la desestructuración del espacio colonial andino: Bolivia 1825-1850», en Del altiplano al desierto. Construcción de espacios y gestación del conflicto, Eduardo Cavieres, ed., pp. 41-81. Valparaíso: Ediciones Universitarias de Valparaíso.

BaLdivia GaLdo, José María

1951 Tacna, Arica y Cobija: páginas históricas. La Paz: Universo. $3^{\text {a }}$ Edición.

Ballester, Benjamín, Alex San Francisco y Francisco Gallardo

2010 «Modo de vida y economía doméstica de las comunidades cazadoras recolectoras del desierto de Atacama en tiempos coloniales y republicanos». Taltalia 3: 21-32.

BERTONIO, Ludovico

1984 Vocabulario de la lengua Aymara [1612], vol. II. La Paz: Ceres.

BitTMann, Bente

1980 «Proyecto de investigación interdisciplinaria en la costa centro-sur andina», en Proyecto de investigación interdisciplinaria en la costa centro-sur andina, Bente Bittmann, María Teresa Ahumada y Cora Moragas, eds., Vol. 1, pp. 11-20. Antofagasta: Departamento de Arqueología. Universidad del Norte. 
1983 «Cobija: panorama etnohistórico en relación a los informes del Dr. José Agustín de Arze» Chungará 10: 147-153.

CAJÍAs, Fernando

1975 La provincia de Atacama 1825-1842. La Paz: Instituto Boliviano de Cultura.

CASASSas CANTó, José María

1974a La región atacameña en el siglo XVII. Datos históricos socioeconómicos sobre una comarca de América meridional. Incluye, en apéndice, la transcripción completa de Libro de Varias Ojas, 1611-1698 de la Parroquia de Chiuchiu, el conjunto documental más antiguo de la región atacameña. Antofagasta: Universidad del Norte.

1974b «Algunas noticias sobre los partidos de Arica y Tarapacá hacia fines del siglo XVIII y principios del siglo XIX». Norte Grande 1 (2): 217-226.

CASTRo, Victoria

2001 «Atacama en el tiempo. Territorios, identidades, lenguas (Provincia El Loa, II Región)» Anales de la Universidad de Chile, VI serie, 13: 27-70.

2009 De ídolos a santos. Evangelización y religión andina en los Andes del sur, Santiago: Fondo de Publicaciones Americanistas, Universidad de Chile / Centro de Investigaciones Diego Barros Arana / Dirección de Bibliotecas, Archivos y Museos.

Castro, Victoria, Carlos Aldunate y Varinia Varela

2012 «Paisajes culturales de Cobija, costa de Antofagasta, Chile». Revista de Antropología 26 (2): 97-128.

D'OrBignY, Alcides

1945 Viaje a la América Meridional [1835]. Buenos Aires: Editorial Futuro.

FIFER, J. Valerie

1976 Bolivia. Territorio, situación y política desde 1825. Buenos Aires: Editorial Francisco de Aguirre.

KENT, María Luisa

2009 «Organización de la República Boliviana (1825-1828)», en Sucre, soldado y estadista, Enrique Ayala Mora, ed., pp. 131-158. Quito: Biblioteca de Historia 28. Universidad Andina Simón Bolívar / Corporación Editora Nacional

LARRAÍN, Horacio

1994 «Aportes de Rodulfo Amando Philippi al conocimiento del ethos y cultura de las etnias indígenas del norte de Chile. Homenaje al cumplirse los 90 años de su muerte». Revista Ciencias Sociales 4: 3-18.

LEHNERT SANTANDER, Roberto

1997 Changos: navegantes de mareas. Antofagasta: Universidad de Antofagasta / Instituto de Investigaciones Antropológicas.

LETELIER COSMELLI, Javiera

2011 «Clasificando indios, un ejemplo de la construcción de la categoría changos durante el siglo XVI y XVII en la zona de la actual provincia del Loa». Revista Taltalia 4: 103-115.

2016 «Entre la costa de Cobija y tierras altas: el tráfico arriero a inicios de la República Boliviana». Diálogo Andino 49: 225-234.

LizÁrRAGA, Reginaldo de

1968 Descripción breve de toda la tierra del Perú, Tucumán, Río de la Plata y Chile [1605]. Biblioteca de Autores Españoles, 221. Madrid: Ediciones Atlas. 
Llagostera, Agustín

1982 «Tres dimensiones en la conquista prehistórica del mar. Un aporte para el estudio de las formaciones pescadoras de la costa sur andina», en Actas del VIII Congreso de Arqueología Chilena, pp. 217-245. Santiago: Kultrún.

2005 «Culturas costeras precolombinas en el norte chileno: secuencia y subsistencia de las poblaciones arcaicas», en Biodiversidad marina: valoración, usos, perspectivas ¿Hacia dónde va Chile?, Eugenio Figueroa, ed., pp. 107-148. Santiago: Editorial Universitaria.

Lofstrom, William Lee

1974 «Cobija, Bolivia’s First Outlet to the Sea». The Americas 31 (2): 185-205.

1991 Cobija y el litoral boliviano, vistos por ojos extranjeros 1825-1880. La Paz: Editorial Quipus.

Martínez Cereceda, José Luis

1985 «Información sobre el comercio de pescado entre Cobija y Potosí, hecha por el Corregidor de Atacama, don Juan de Segura (19 de julio de 1591)». Cuadernos de Historia 5: 161-171.

1990 «Asentamiento y acceso a los recursos en Atacama (s. XVII) Charcas», en Economía y comercio en América Hispana, Guillermo Bravo, ed., pp. 13-61. Serie Nuevo Mundo: Cinco Siglos, 5. Santiago: Universidad de Chile.

Mitre, Antonio

1981 Los patriarcas de la plata. Estructura socioeconómica de la minería boliviana en el siglo XIX. Lima: Instituto de Estudios Peruanos.

Novoa, José, Yann Tracol y David LóPez

2008 «Paisaje eco-geográfico de la Región de Atacama», en Libro rojo de la flora nativa $y$ de los sitios prioritarios para su conservación: Región de Atacama, Francisco Squeo, Gina Arancio y Julio Gutiérrez, eds., pp. 13-24. La Serena: Ediciones Universidad de La Serena.

Olguín, Laura, Diego SALAZAR y Donald JACKSON

2014 «Evidencias de navegación y caza de especies oceánicas en la costa pacífica de Sudamérica (Taltal, 7.000 años cal. a.p.)». Chungara 46 (2): 177-192.

Osorio Gonnet, Cecilia

2004 «Ser hombre en la pampa. Aproximación hacia los rasgos de masculinidad del peón chileno en las tierras del salitre, 1860-1880», en Arriba quemando el sol. Estudios de historia social chilena: experiencias populares de trabajo, revuelta y autonomía (1830-1940), M. Fernández, A. Harambour, R. Henríquez, J. Iturriaga, L. Ossandón, C. Osorio, D. Palma y F. Purcell eds., pp. 91-110. Santiago de Chile: Editorial Lom.

PhILLIPI, Rudolfo

1860 «Viage al Desierto de Atacama hecho de orden del Gobierno de Chile en el verano 1853-1854». Halle en Sajonia: Librería Eduardo Antón.

RosTwOROWSKI, María

1986 «La región del Colesuyu». Chungará 16-17: 127-135.

RUSCHENBERGER, William

1835 Three Years in the Pacific Containing Notice of Brazil, Chile, Bolivia y Perú in 1831, 1832, 1833, 1834 [vol 1]. Londres: Richard Bentley, New Burlington Street. 
RuSSELL, William H.

1890 A Visit to Chile and the Nitrate Fields of Tarapaca, etc. Londres: J. S. Virtue \& Co. Salazar, Diego, Victoria Castro, Jaie Michelow, Hernán Salinas, Valentina Figueroa y Benoît MiLLE

2010 «Minería y metalurgia en la costa arreica de la región de Antofagasta, Norte de Chile». Boletín del Museo Chileno de Arte Precolombino 15 (1): 9-23.

SANDWEISS, Daniel

2003 «Terminal Pleistocene through MidHolocene Archaeological Sites as Paleoclimatic Archives for the Peruvian Coast. Palaeogeography». Palaeoclimatology, Palaeoecology 194: 23-40.

SANHUEZA, Cecilia

1992 «Tráfico caravanero y arriería colonial en el siglo XVI». Estudios Atacameños 10: $173-187$

Tellez, Eduardo y Osvaldo Silva

2012 «Noticias sobre los inicios históricos de Lamar (Cobija), primer puerto de Bolivia en el Pacífico (1828)». Cuadernos de Historia 37: 241-248. https://doi.org/10.4067/ S0719-12432012000200009. 